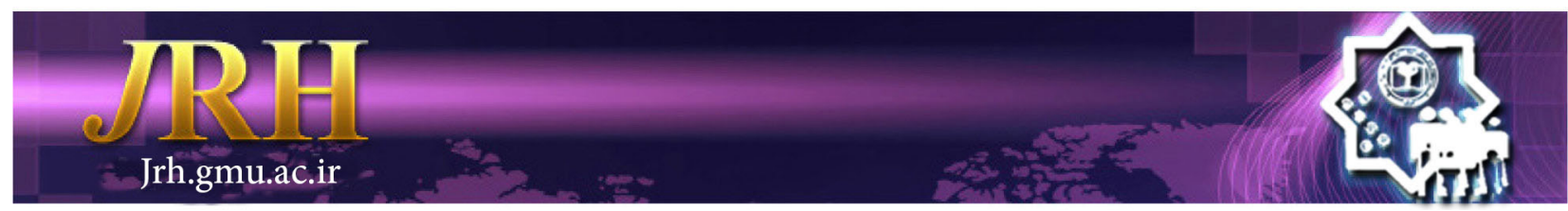

\title{
The prevalence of drug abuse among the students of Zahedan
}

Sayed Aliakbar Refahi ${ }^{1}$, Saeid Mohtasham², Mohammad Reza Raeisoon $^{3}$

\author{
Journal of Research \& Health \\ Social Development \& Health Promotion \\ Research Center \\ Vol. 8, No.5, Sep \& Oct 2018 \\ Pages: $435-441$ \\ DOI: $10.29252 / j r h .8 .5 .435$ \\ Original Article
}

\begin{abstract}
1. Department of Clinical Psychology, Shiraz University, Shiraz, Iran

2. Department of Psychiatrist, Faculty of Medicine, Birjand University of Medical Sciences, Birjand, Iran

3. Correspondence to: Department of Social Medicine, Social Determinants of Health Research Center, Faculty of Medicine, Birjand University of Medical Sciences, Birjand, Iran

Email: raeisoon49@gmail.com
\end{abstract}

Received: 10 Apr 2014

Accepted: 3 Jan 2016

How to cite this article: Refahi SA, Mohtasham S, Raeisoon MR. The prevalence of drug abuse among the students of Zahedan. $J$ Research \& Health2018; 8(5): 435- 441.

\begin{abstract}
Addictive substance abuse is one of the most important problems of human societies and one of the major challenges to the social, health and political world. Although the problem is not confined to specific age groups, young people, including university students, are among the main groups at risk. Therefore, this study examined the prevalence of addictive substance abuse among students of Islamic Azad university, Zahedan. This descriptive, cross-sectional study was conducted on 1014 students studying at the Islamic Azad University of Zahedan, using the cluster sampling method, in due observance of gender, college, and program level distribution. The data were collected using the high-risk behaviors questionnaire and a demographics form. The greatest frequencies comprised, respectively, of waterpipe smoking (40.04\%), cigarette (22\%), alcohol (12.06\%), and opium (7.5\%). Smoking prevalence in male and female students were respectively $56.7 \%$ and $26.1 \%$. Cigarette smoking rates among female and male students were of $6.8 \%$ and $39.1 \%$ prevalences. Alcohol consumption among female and male students had 2.4\% and $13.5 \%$. Study results indicate a high prevalence of drug abuse among students was addiction. This demands greater attention to preventive and educational measures and interventions for this vulnerable group of society.
\end{abstract}

Keywords: Alcohol, Drug Abuse, Prevalence, Smoking

\section{Introduction}

Drug abuse should be taken as one of the most obvious biopsychosocial problems that can weaken the foundation of the individual, family, social, and cultural life of a person and society and make it collapse [1]. Drug abuse is a prevalent phenomenon in the world that has invaded human societies as a major social harm $[2,3]$.

The relationship between drug abuse and other deviations and its unbreakable association with problems such as mental disorders, escape from home, aggressive and violent social behaviors, robbery, delinquency, academic failure, disinterest in education, suicide attempts, and prostitution emphasize the importance of drug abuse. Based on epidemiological studies, illicit drug use is more common in young adults than in other age groups [4].

Drug abuse has dramatically increased in Iran to become a major social problem. Based on statistics released in 2003, the age at onset of drug abuse has decreased to 14-16 years in Iran [5]. According to a survey by the Ministry of Health and Medical Education in 2001 and statistics available at the Official Document System of the United Nations, there were at least 3,761,000 drug users in Iran in 2001, and the annual growth rate or incidence of addiction is $8 \%$ in the country; that is, three 
times higher than the population growth rate, which is $2.3 \%$ [6].

Statistics also suggest that $34 \%$ of divorces in Iran are caused by addiction and problems related to drug abuse [7].

Iran is not only one of the main drug transit routes because of sharing a border with the largest drug production center [8], but has itself become a good market for the use of drugs produced in Afghanistan. There are major addiction-related problems in Iran due to its young population [9].

Moreover, the rapid expansion of drug abuse and its related problems in students and harmful consequences such as the lack of academic motivation, academic failure, physical and mental illnesses, suicide, careless driving, vandalism, aggressive behaviors, the lack of a sense of identity and high-risk sexual behaviors introduced by Cooper and Perkins reveal the need for developing plans and preventive intervention strategies in universities [10]. One of the prerequisitesforany planning is to learn the existing conditions and the status of drug abuse among students. Experts now believe that epidemiological studies are the first step to the development of preventive programs [11]. This study focused on several objectives, including identification of drug varieties and their associated problems, identification of subgroups at risk, evaluation and analysis of background and environmental developments as a measure of the effectiveness of preventive programs, identification of intermediate variables, and provision of statistical and normative indicators for planning and application in peer groups and other influential groups.

Few studies have examined the epidemiology of drug abuse in Iranian students, and there are some methodological failures in thestudies existing on the subject and unlike the present study, most of them have not examinedthe prevalence of drug abuse by estimating indicators such as lifetime prevalence, prevalence in the past year, and prevalence in the past month. The present study was therefore conducted to examine the epidemiology of drug abuse among the students of Islamic Azad
University, Zahedan Branch.

\section{Method}

The population studied in this study consisted of all the male and female students of all academic levels at Islamic Azad University, Zahedan Branch, in the academic year 2013.

The participants were selected through multi-stage cluster sampling and the universityfaculties were taken as categories and themajors of study as clusters, and a random class of the same yearwas selected from the different majors of study in each faculty using simple random sampling. A total of 1025 students were eventually selected. Data were collected using aresearchermadequestionnaire along with interviews. The questionnaire was developed in two parts. The first part consisted of six personaldemographic items, and the second part was about high-risk behaviors. The second part wasdesigned based on the Youth Risk Behavior Surveillance System (YRBSS) developed by the American Centers for Disease Control and Prevention (CDC) in 1989 for assessing high-risk behaviors causing mortality, illness, and social problems among adolescents and adults. Burner et al. evaluated the reliability of the 53-item YRBSS using test-retest, and the kappa coefficient of all the items was calculated as 0.65 to 0.91 . Burner et al. also examined the 72-item adolescent and young adult risk behavior scale on male and female high school students from different populations in the US using a two-week test-retest. The researchers calculated the kappa coefficient of all the 72 items in order to compare the prevalence of high-risk behaviors in the test and retest by group, and reported coefficients of 0.63 to 0.91 .

After the validity of the Persian version of the adolescent and young adult risk behavior scalederived by Bakhshani et al. from the noted questionnaires was verifiedby psychiatrists and psychologists, the scale was evaluated in a pilot study among30 people on two occasions within a two-week 
interval. The consistency between participants' responses to all the major items was higher than $85 \%$. The analysis of the data of 200 school students randomly divided into two groups showed no significant differencesin responses (i.e. the relative frequency of the items) between the two groups. The Persian version of the adolescent and young adult risk behavior scale consists of 69 items that not only assess demographic characteristics, but also examinedifferent high-risk behaviors based on their lifetime prevalenceand frequency andtheir prevalence and frequency in the past year and in the past month (Reference No. for the study by Bakhshani et al.). This study used the Persian version of the scale whose validity and reliability had been confirmed by Bakhshani et al [2].

In this study, drug abuse has been used to refer to the students'use of drugs even just once in their life and even though the student might have no addictions to a particular drug. After selecting the participants, the researcher attended the students' classes and briefed them on how to complete the scale without mentioning their first name and family name, and ensured them of the confidentiality of their information, and asked them to complete the scale individuallyin the assigned period.

The collected data were analyzed in SPSS-15 using descriptive statistics and the Chi-square test.

\section{Results}

Of the 1025 copies of the scale that were distributed among the students, 11 were returned with illegible or contradictory information and were thus excluded, and 1014 were analyzed. A total of $74.1 \%$ of the students were studying toward a bachelor's degree, $23 \%$ toward an associate degree, and $2.9 \%$ toward a master's degree. A total of $21.1 \%$ of the students were aged $18-20,26.2 \%$ were 20 22 , and $51.6 \%$ were 22 orover (Table 1 ).

Table 1 The demographic characteristics of the participating students

\begin{tabular}{|c|c|c|c|c|}
\hline & \multicolumn{2}{|l|}{ Variable } & $\%$ & $\mathrm{~N}$ \\
\hline \multirow{2}{*}{ Gender } & \multicolumn{2}{|l|}{ Female } & 53.1 & 538 \\
\hline & \multicolumn{2}{|l|}{ Male } & 46.9 & 467 \\
\hline \multirow{5}{*}{ Faculty } & \multicolumn{2}{|l|}{ Humanities } & 33.4 & 339 \\
\hline & \multicolumn{2}{|c|}{ Medical Sciences } & 21.3 & 216 \\
\hline & \multicolumn{2}{|c|}{ Technical-Engineering } & 28.8 & 292 \\
\hline & \multicolumn{2}{|c|}{ Teacher Training } & 10.2 & 102 \\
\hline & \multicolumn{2}{|c|}{ Basic Sciences } & 6.3 & 64 \\
\hline \multirow{2}{*}{ Region } & \multicolumn{2}{|l|}{ Native } & 73.7 & 849 \\
\hline & \multicolumn{2}{|l|}{ Non-Native } & 16.3 & 165 \\
\hline \multirow{6}{*}{$\begin{array}{l}\text { Level of } \\
\text { Education }\end{array}$} & \multirow{2}{*}{$\begin{array}{l}\text { Associate } \\
\text { Degree }\end{array}$} & Female & 12.1 & 122 \\
\hline & & Male & 10.9 & 111 \\
\hline & \multirow{2}{*}{$\begin{array}{l}\text { Bachelor's } \\
\text { Degree }\end{array}$} & Female & 39.6 & 401 \\
\hline & & Male & 34.5 & 349 \\
\hline & \multirow{2}{*}{$\begin{array}{l}\text { Master's } \\
\text { Degree }\end{array}$} & Female & 1.4 & 14 \\
\hline & & Male & 1.5 & 15 \\
\hline \multirow{4}{*}{ Age (year) } & \multicolumn{2}{|l|}{$18-20$} & 21.1 & 214 \\
\hline & \multicolumn{2}{|l|}{$20-22$} & 26.2 & 266 \\
\hline & \multicolumn{2}{|l|}{$\geq 22$} & 51.6 & 523 \\
\hline & \multicolumn{2}{|l|}{ Unknown } & 1.1 & 11 \\
\hline
\end{tabular}

The highest prevalence of hookah smoking was $40.4 \%$ during the students' entire life and $15.3 \%$ in the past month. The prevalence of alcohol consumption was $12.6 \%$ during the students' entire life and $4.1 \%$ in the past month. The prevalence of alcohol consumption during the entire life was $4.7 \%$ in the female students and $21.6 \%$ in the male students; in the past 
month, it was $1.9 \%$ in the female students and $6.6 \%$ in the male students. In addition, $4.1 \%$ of the students had used opium in their lifetime and $2.3 \%$ had used it in the past month.

Table 2 A comparison of the lifetime prevalence and prevalence in the past month of drug abuse in the students by gender

\begin{tabular}{|c|c|c|c|c|c|c|c|c|c|c|}
\hline & \multicolumn{4}{|c|}{ Lifetime prevalence } & \multicolumn{4}{|c|}{ Prevalence in the past month } & & \\
\hline & $\%$ & $\mathrm{~N}$ & $\%$ & $\mathrm{~N}$ & $\%$ & $\mathrm{~N}$ & $\%$ & $\mathrm{~N}$ & $\%$ & $\mathrm{~N}$ \\
\hline Female & 2.4 & 13 & 97.2 & 524 & 0.3 & 7 & 98.7 & 530 & 100 & 537 \\
\hline Male & 13.3 & 63 & 86.7 & 410 & 6.4 & 30 & 93.6 & 443 & 100 & 473 \\
\hline
\end{tabular}

According to Table 2, the lifetime prevalence of drug abuse was $7.5 \%$ in the students and its prevalence in the past month was $3.7 \%$. By gender, the lifetime prevalence was $2.4 \%$ in the female students and $13.3 \%$ in the male students; the prevalence in the past month was $0.3 \%$ in the female students and $6.4 \%$ in the male students.

Table 3 A comparison of the students' prevalence of cigarette smoking during the entire life, in the past month and in the past year by gender

\begin{tabular}{|c|c|c|c|c|c|c|c|c|c|c|}
\hline & \multicolumn{4}{|c|}{ Lifetime prevalence } & \multicolumn{4}{|c|}{ Prevalence in the past month } & & \\
\hline & \multicolumn{2}{|c|}{ Yes } & \multicolumn{2}{|c|}{ No } & \multicolumn{2}{|c|}{ Yes } & \multicolumn{2}{|c|}{ No } & \multicolumn{2}{|c|}{ Total } \\
\hline & $\%$ & $\mathrm{~N}$ & $\%$ & $\mathrm{~N}$ & $\%$ & $\mathrm{~N}$ & $\%$ & $\mathrm{~N}$ & $\%$ & $\mathrm{~N}$ \\
\hline Female & 6.8 & 36 & 93.2 & 497 & 2.3 & 12 & 97.7 & 521 & 100 & 533 \\
\hline Male & 39.1 & 185 & 60.9 & 288 & 13.5 & 64 & 86.5 & 409 & 100 & 473 \\
\hline Total & 22 & 221 & 78 & 785 & 7.6 & 76 & 92.4 & 930 & 100 & 1006 \\
\hline
\end{tabular}

Based on Table 3, overall, the lifetime prevalence of cigarette smoking and its prevalence in the past year and in the past month was $22 \%$, $11.7 \%$, and $7.6 \%$, respectively. By gender, however, the lifetime prevalence was $6.8 \%$ in the female and $39.1 \%$ in the male students, the prevalence in the past year was $3.9 \%$ in the female and $20.5 \%$ in the male students, and the prevalence in the past monthwas $2.3 \%$ in the female and $13.5 \%$ in the male students.

Table 4 A comparison of the prevalence of hookah smoking in the students by gender over time

\begin{tabular}{|c|c|c|c|c|c|c|c|c|c|c|}
\hline & \multicolumn{4}{|c|}{ Lifetime prevalence } & \multicolumn{4}{|c|}{ Prevalence in the past month } & & \\
\hline & \multicolumn{2}{|c|}{ Yes } & \multicolumn{2}{|c|}{ No } & \multicolumn{2}{|c|}{ Yes } & \multicolumn{2}{|c|}{ No } & \multicolumn{2}{|c|}{ Total } \\
\hline & $\%$ & $\mathrm{~N}$ & $\%$ & $\mathrm{~N}$ & $\%$ & $\mathrm{~N}$ & $\%$ & $\mathrm{~N}$ & $\%$ & $\mathrm{~N}$ \\
\hline Female & 26.1 & 140 & 73.9 & 397 & 8.4 & 45 & 91.6 & 491 & 100 & 537 \\
\hline Male & 56.7 & 268 & 43.3 & 205 & 23 & 109 & 77 & 364 & 100 & 473 \\
\hline Total & 40.4 & 40 & 59.6 & 602 & 15.3 & 154 & 84.7 & 855 & 100 & 1010 \\
\hline
\end{tabular}

Based on Table 4, the overall prevalence of hookah smoking was $40.4 \%$ during the entire life, $27.1 \%$ in the past year, and $15.3 \%$ in the past month. By gender, the lifetime prevalence was $26.1 \%$ in the female and $56.7 \%$ in the male students, the prevalence in the past year was $15.8 \%$ in the female and $40 \%$ in the male students, and the prevalence in the past monthwas $8.4 \%$ in the female and $23 \%$ in the male students.

\section{Discussion}

The results revealed a relatively low prevalence for highly addictive drugs (opium, cannabis, crystal meth, heroin, etc.) and a high prevalence for light addictive drugs (cigarette, hookah, and alcohol). The prevalence of drug abuse was $7.5 \%$ during the students' entire life, $5.2 \%$ in the past year, and $3.7 \%$ in the past month. The prevalence of cigarette smoking was $22 \%$ during the students' entire life, $11.7 \%$ in the past year, and $7.6 \%$ in the past month. The prevalence of alcohol consumption was $12.6 \%$ during the students' entire life, $7 \%$ in the past year, and $4.1 \%$ in the past month. The prevalence of hookah smoking was 
$40.4 \%$ during the students' entire life, $27.1 \%$ in the past year, and $15.3 \%$ in the past month. The results about the prevalence of drug abuse in the students showed that $7.8 \%$ of allthe students use drugs, which is consistent with the resultsobtained bySerajzadeh [12], who reported the prevalence of drug abuse as $10 \%$. Based on a National Institute on Drug Abuse (NIDA) report [13], the prevalence of drug abuse is $51 \%$ among students in the US and $43 \%$ among students in the UK. Given the present findings, the prevalence of drug abuse is much higher among students of other countries compared to students in Iran, which may be due to these societies'less adherence to ethical principles and religious doctrinesand the general lack of a warm family environment in them.

In the present study, the prevalence of cigarette smoking was $22 \%$ during the students' entire life, $11.7 \%$ in the past year, and $7.6 \%$ in the past month. The prevalence of cigarette smoking was reported as $21.4 \%$ in Serajzadeh's study [12], $24.2 \%$ in a study by Siyam [3], and 10-68.2\% in some other studies [14-16]. According to the NIDA report [13], the prevalence of cigarette smoking is $73 \%$ in students in the US and $47 \%$ in students in the Netherlands.

The consistency between the present findings and the results of other studies conducted in Iran may be due to the easy access to cigarettes in all parts of Iran and the studies' similar methods and design, sampling, assessment instruments, and data filtering before the statistical analysis.

In the present study, the prevalence of alcohol consumption was $12.6 \%$ during the students' entire life, $7 \%$ in the past year, and $4.1 \%$ in the past month. The prevalence of alcohol consumption was $20 \%$ in Serajzadeh's study [12].

The prevalence of alcohol consumption was $17 \%$ in a study by Zarrabi [17]. According to the NIDA report [13], the prevalence of alcohol consumption is $81.7 \%$ in students in the US and $73.2 \%$ in students in the UK.

High levels of alcohol consumption(about 80$90 \%$ ) have been reported among physicians and medical students in studies conducted in western countries $[14,16]$. The inconsistency between the present findings and the results of other domestic studies appears to be due to the students' less access to alcohol in their geographical location and province, as $90 \%$ of the alcohol imported to Iran travels through the western provinces based on a report of the Iran Drug Control Headquarters. The inconsistency between the present findings and the results of foreign studies on the subjectmay be due to Iranians' religious and cultural beliefs and the general ban on alcohol in Iran.

The prevalence of hookah smoking was $40.4 \%$ during the students' entire life, $27.1 \%$ in the past year, and $15.3 \%$ in the past month. Dehghani reported the prevalence of hookah smoking as $15.9 \%$ [18]. A study conducted to measure the prevalence of high-risk health behaviors in the students of higher education institutions in Khorramabad, Iran,revealed the prevalence of hookah smoking as $29.7 \%$ and the prevalence of cigarette smoking as $25.1 \%$, which are higher than the rates reported for other drugs [19]. A study in Syria reported the prevalence of hookah smoking among its medical students as $23.5 \%$ [20]. The disparity between the present findings and the results of other studies appears to be due tothe different culture and customs of people in this region and the common use of the hookah in latenight gatherings. Despite the warnings by the Ministry of Health aboutthe adverse effects of hookah smoking being several times higher than the adverse effects of cigarette smoking, hookah smoking was almost twice as common as cigarette smoking in the present study. In this study, the prevalence of drug abuse was significantly higher in the male students than in the female students, which is consistent with the results of several studies conducted in Iran [3,19,21] and abroad [14,16,20,22]. Men are at a higher risk of drug abuse than women are. These results are also consistent with theresults obtained by Malchyur, Chestang and Goldberg, Milani et al., Karbakhsh and SalehianZandi [23,24]. In support of this finding,Mohammadi [25] showed that women view drug abuse more negatively than men do. In some recent studies, the prevalence of drug 
abuse has shown a considerable increase among women too, and according to some studies, this ratedoes not differ significantly between women and men [22].

\section{Conclusion}

The rapid expansion of drug abuse and its related problems in students and harmful consequences such as the lack of academic motivation, academic failure, physical and mental illnesses, suicide, vandalism, aggressive behaviors, lack of a sense of identity and high-risk sexual behaviors reveal the need for developing plans and preventive intervention strategies in universities.

\section{Acknowledgments}

The authors appreciate the support of the vicechancelleries of education and research of Islamic Azad university, Zahedan branch.

\section{Contribution}

Study design: SAR, SM

Data collection and analysis: MR, SAR

Manuscript preparation: MR, SM

\section{Conflict of Interest}

The authors declare that they have no competing interests.

\section{Funding}

The author received no financial support for this research.

\section{References}

1- Taremian F, Bolhari J, Peyravi H, Asgari A. Drug use prevalence among students of universities of medical sciences in Tehran. Addiction Research2014; 7(28): 9-21. 2- Bakhshi Poor Rudsari A. A guide for prevention \& treatment of substance abuse. 1st ed. Tehran: Salman; 2004. 3- Siam SH. Drug abuse prevalence in male students of different universities in Rasht in 2005. Tabib-eShargh2007; 8(4): 279-85.

4- Sadock VA, Sadock BJ. Kaplan \& Sadock`s synopsis of psychiatry. 8th ed. Philadelphia: Williams \& Wilkins; 2003.

5- Shyangwa PM, Joshi D, Lal R. Alcohols and other substance use, abuse among junior doctors and medical students in a teaching institute. JNMA J Nepal Med Assoc2007; 46(167): 126-9.
6- Foorootani M. The knowledge about addiction in Larestan University students in 2003. In 3rd National addiction Congress in Iran; 2004. pp: 218.

7- Effati J. Addiction: prevention or treatment?. 1st ed. Yazd: Nikoo Ravesh publisher; 2000.

8- Cooke DJ, Baldwin PJ, Howison J. Psychology in prisons. Translated by: Mohamadi A. Tehran: State prisons and security and corrective measures organization; 2000. pp: 89-90.

9- Gravett S. Coping with prison: a guide to practitioners on the realities of imprisonment. 1st ed. London: Cassell; 1999.

10- Cooper ML. Alcohol use and risky sexual behavior among college students and youth: Evaluating the evidence. J Stud Alcohol Suppl2002; (14): 101-17.

11- Rieson M, Miri MR, Dastjerdi R, Sharifzadeh G. Prevalence of mental disorders in Birjand-2010. Journal of Birjand University of Medical Sciences 2012; 19(1):81-7.

12- Serajzadeh H. Students with drug problems, family background and circumstances. (Unpublished report). Ministry of science, research and technology, office of community planning and cultural studies; 2004.

13- Johnston LD, O’Malley PM, Bachman JG, Schulenberg JE. Monitoring the future: national survey results on drug use, 1975-2003. Volume II, College students and adults ages 19-45 (NIH Publication No. 04-5508). Bethesda, MD: National Institute on Drug Abuse; 2004.

14- Shyangwa PM, Joshi D, Lal R. Alcohols and other substance use/abuse among junior doctors and medical students in a teaching institute. JNMA J Nepal Med Assoc2007; 46(167): 126-9.

15- Baldwin DC Jr, Hughes PH, Conard SE, Storr CL, Sheehan DV. Substance use among senior medical students: A survey of 23 medical schools. JNMA J Nepal Med Assoc 1991; 265(16): 2074-8.

16- Akvardar Y, Demiral Y, Ergor G, Ergur A. Substance use among medical students and physicians in a medical school in Turkey. Soc Psychiatry Psychiatr Epidemiol2004; 39(6): 502-6.

17- Zarrabi H, Najafi K, Shirazi M, Borna S, Sabahi E, Nazifi F. Prevalence of substance use among students of Guilan University of Medical Sciences (20052006). The Journal of Qazvin University of Medical Sciences2009; 12(4): 69-74.

18- Dehghani K, Zare A, Dehghani H, Sedghi H, Poormovahed Z. Drug abuse prevalence and risk factors in students of Shaheed Sadoughi university of medical sciences, Yazd. Journal of Shahid Sadoughi University of Medical Sciences2010; 18(3): 164-9.

19- Momen-Nasab M, Najafi SS, Kaveh MH, Ahmad Pour F. Prevalence of risky health behaviors among the students of Khorramabad universities. Yafte2007; 8(2): 23-9. 
20- Almerie MQ, Matar HE, Salam M, et al. Cigarettes and waterpipe smoking among medical students in Syria: a cross-sectional study. Int $J$ Tuberc Lung Dis2008; 12(9): 1085-91.

21- Kheirkha F. Epidemiology of dependence and substance abuse in students of medical science of Babol University. Final report. Tehran (IR): Iranian research institute for information sciences and technology (MSRT); 2004.

22- Sadeghi M, Navidi M. Substance use among medical residents in Tehran, Iran. Addict Disord Their Treat2005; 4(3): 121-4.
23- Melchior M, Chastang JF, Goldberg P, Fombonne E. High prevalence rates of tobacco, alcohol and drug use in adolescents and young adults in France: results from the GAZEL Youth study. Addict Behav2008; 33(1): 122-33..

24- Karbakhsh M, Salehian Zandi N. Acute opiate overdose in Tehran: the forgotten role of opium. Addict Behav2007; 32(9): 1835-42.

25- Mohammadi M. Factors influencing resiliency in individuals at risk for substance abuse. [dissertation]. Tehran: University of social welfare and rehabilitation sciences 2005; pp: 126.

Copyright $\odot 2016$ ASP Ins. This open-access article is published under the terms of the Creative Commons Attribution-NonCommercial 4.0 International License which permits Share (copy and redistribute the material in any medium or format) and Adapt (remix, transform, and build upon the material) under the Attribution-NonCommercial terms. 